\title{
Metodologia Ativa Dentro Da Sala De Aula Em Relação Ao Ensino-Aprendizagem
}

\section{Active Methodology Within The Classroom In Relation To Teaching And Learning}

DOI: $10.54019 /$ sesv2n3-013

\section{Prof. Doutor. Luís Fernando Ferreira de Araújo \\ E-mail: lusfernandoaraujo40@gmail.com}

\section{Prof. Doutor Euclides Alves Vital Junior}

\section{Resumo}

A metodologia ativa fornece elementos aos alunos para falar, ouvir, entender, ler e viver o mundo incentiva a integração escola-sociedade. Possibilita o ato de ensinar, aprender e apropriar-se do contexto sociocultural em que o aluno está inserido. O participante é o protagonista ativo do processo, na construção do seu conhecimento e da sua formação.

Palavras-chave: metodologia ativa, alunos, ensinar, conhecimento e formação.

\section{Abstract}

The active methodology provides elements for students to speak, listen, understand, read and live the world encourages school-society integration. It enables the act of teaching, learning and appropriation of the socio-cultural context in which the student is inserted. The participant is the active protagonist of the process, in the construction of its knowledge and its formation.

Keywords: active methodology, students, teaching, knowledge and training.

\section{INTRODUÇÃO}

O tema deste artigo surgiu a partir das reflexões e dúvidas como uma metodologia ativa poderia ser usada como interação ensino-aprendizagem, atribuindo a ela um caráter mais linguístico. O propósito foi o de apresentar uma nova figura de professor com suas ferramentas de trabalho, os equipamentos mais sofisticados da área de tecnologia auxiliar, no seu empenho em ensinar com dinamismo e criatividade. Esse professor, com habilidades em manipular estas ferramentas é denominado professor mediador pedagógico, por facilitar a transposição de uma mensagem consistente e atualizada. A metodologia ativa 
procura estabelecer correlações com temas de maior interesse da cultura estudantil, que envolva uma aproximação crítica da escola com a realidade.

A metodologia ativa pretende subsidiar elementos aos alunos para falar, ouvir, entender, ler, refletir e viver o mundo, buscando a integração escolasociedade. São transformações vindas da onipresença do conhecimento e da informação. Ajudam os professores a envolverem os alunos nas discussões de ideias, desafios, julgamentos e críticas. Com isso, o professor tem a função de manter um diálogo constante com base no conhecimento empírico da prática de ensino.

Criar o novo não é tarefa para qualquer um e cabe ao educador assumir esse desafio. O ser humano gosta do conhecido, do fácil, daquilo que já é. O desafio dói, causa desconforto e essa é a tarefa do educador: provocar, incomodar. O que já aconteceu serve como base, ponto de partida e dá segurança para exercer o poder que é garantido, que foi conquistado de forma tão dura, porém prazerosa. Orientar esse poder da forma adequado compete ao educador.

Para que haja educação de adultos, a superação de desafios, a resolução de problemas e a construção de novos conhecimentos a partir de experiências prévias, são necessárias para impulsionar as aprendizagens (FREIRE, 1996, p.20).

Muitos dos alunos vêm de famílias com poucos recursos intelectuais, financeiros e culturais. Esse aluno idealiza a figura do professor, a vida acadêmica, a cultura, um mundo que ele desconhece e que pode the oferecer mais, apontar novos caminhos. Deve - se utilizar essa imagem esse poder que delegado ao professor e não destruí-lo com a falsa proposta de aproximar - se do aluno. Aproximar-se dele é em primeiro lugar enxergá-lo na sua real condição que não necessariamente coincide com a proposta educacional da instituição em que se encontra. Só assim haverá a possibilidade de uma adaptação para que tenha acesso ao conhecimento que afinal ele veio buscar, sejam seus propósitos conscientes e lícitos dentro dos conceitos da educação ou não.

O processo pedagógico estabelecido visa desenvolver competências relacionadas à prática profissional. Na análise de Perrenoud (1997, p. 35): 
Toda competência está, fundamentalmente, ligada a uma prática social de certa complexidade. Não a um gesto dado, mas sim a um conjunto de gestos, posturas e palavras inscritos na prática que lhes confere sentidos e continuidade.

Decorre disso a necessidade de identificar a posição exata em que o aluno se encontra na sociedade e na sua vida pessoal para não idealizar e trabalhar com um suposto ser que na verdade não existe, o que fatalmente o conduzirá ao insucesso. A percepção da pessoa a quem o professor atende é passo de partida no traçado do caminho pedagógico mais adequado.

Conforme Meirieu (1998) é necessária à compreensão do "triângulo pedagógico" para criar situações de aprendizagem sem deixar-se atrair por nenhum dos três polos: educando-saber-educador. Para isso é importante que o educador tenha consciência do seu papel e da sua importância. O educador é também um cidadão inserido em seu meio social com ideias, ideais e conhecimentos já estruturados. Esses conhecimentos e experiências prévias podem e devem ser utilizados para criar situações interessantes. Tanto o educador quanto o educando apresentam experiências de vida, conhecimentos anteriores. Além disso, os sentimentos de ambos podem ser persuadidos adequadamente para melhorar esse processo. Meirieu (1998, p.80-81) ressalta ainda:

\begin{abstract}
Quem pode querer ignorar a relação pedagógica, este encontro entre pessoas vivas e cheias de desejos, este conjunto de fenômenos afetivos, de transferências e contratransferências, que estão sempre presentes na sala de aula? Não se pode escolher, por simples comodidade, a suspensão da afetividade: primeiro, porque essa decisão, é claro, seria ela própria uma escolha afetiva, alimentada, na maioria das vezes, pela preocupação consigo, pelo medo do outro ou pelo desejo estranho de melhor exercer seu poder camuflando a natureza do mesmo; depois, porque uma atividade cognitiva, ainda que perfeitamente teorizada, não pode ficar sem a energia do desejo que lhe dá vida e força; enfim, porque seria estúpido negar o aspecto determinante, na aprendizagem, dos fenômenos de identificação e de sedução. Sabe-se, de fato, que a vontade de seduzir anima qualquer educador, mesmo que ele quase não o confesse, mesmo anuncie o contrário, fingindo ignorar que a recusa de seduzir pode vir reforçar a sedução...
\end{abstract}

Como lidar com esses conceitos, sedução, conhecimento, poder e aprendizagem de forma adequada? Mantendo os objetivos e o foco no processo de aprendizagem, lidando de forma ética com essas relações delicadas. Não fugindo ao compromisso. Para isso o poder é emprestado ao professor apenas 
como mais uma estratégia de ensino. Não se pode deixar, no entanto, que a vaidade transforme esse instrumento.

Experimentam-se as angústias e dúvidas durante a própria formação acadêmica. Passa-se pelos testes e vence-se, chega-se ao poder que é imprescindível no desempenho do trabalho do professor. Mas esse poder tem limites: o outro é o objetivo não o si mesmo. E isso exige coragem, de abrir mão das vaidades. Só assim realmente é possível ver o sujeito que motiva tantos pensamentos, teorias de aprendizagem, tanto interesse de todas as áreas relacionadas à educação.

Para Bergamann \& Sams (2012, p.11), "o conceito de sala de aula invertida, é feito em sala de aula, agora é executado em casa, e o que tradicionalmente é feito como trabalho de casa, agora é realizado em sala de aula"

Como a novidade assusta, e na maioria das vezes não é desejada no primeiro momento, surgem as desconfianças e constantes questionamentos para com aqueles que podem realmente instigar, provocar: o professor, educador, formador de opiniões, exemplo de conduta, mentor, objeto de paixão, seja qual for a denominação. Todas podem ser ferramentas em favor do outro, o aluno. O conhecimento não pertence ao professor, nem a seu mestre ou àqueles que lhe permitiram chegar a seu título. É algo maior que pertence à essência do ser humano, à alma, não a qualquer academia. Aquele que pensa que detém o conhecimento engana-se não sabe ainda controlar suas vaidades e ambições. Somos apenas vetores do conhecimento responsáveis também por escolher quando e de que forma ele será apresentado ao aluno, o sujeito, o verdadeiro motivo de todas as teorias de aprendizagem.

O conhecimento e o domínio das estratégias é uma ferramenta que o professor maneja de acordo com sua criatividade, sua reflexão e sua experiência, para alcançar os objetivos da aprendizagem (ABREU e MASSETTO, 1990).

Com isso, a metodologia ativa tem que despertar no aluno uma curiosidade e ao mesmo tempo favorecer uma motivação autônoma e também possibilitá-lo uma consciência crítica que atenda as suas necessidades como recurso didático e pedagógico para a formação do aluno na sociedade.

Por meio da metodologia ativa, criar-se-á oportunidades para os alunos, pois eles refletirão a sua importância no cotidiano escolar, o que auxiliou no 
processo ensino-aprendizagem, fazendo-se necessário para que os recursos aplicados em sala de aula sejam significativos para o ensino, oferecendo possibilidades de conhecer o processo de produção de ensino e aprendizagem. Compreendendo esta nova forma de pensar e produzir conhecimento proposto pela utilização deste recurso pedagógico, podendo assim assegurar à educação a melhoria de sua qualidade em sala de aula. Desta forma, trazer a metodologia ativa para o contexto da sala de aula, poderá originar discussões, questionamentos e contribuições para um melhor entendimento do processo criativo e interativo dos alunos a favor da educação.

Neste sentido, o objetivo da aula com a utilização da metodologia ativa será conquistar os alunos por meio da interatividade no exercício de ensino e aprendizagem, bem como apresentar um plano de trabalho que assegure mudanças na maneira de ensinar. Oferecemos aos alunos um entretenimento, informação e educação, contribuindo para a formação e aproximação com os conteúdos pedagógicos, sendo só possível com a mediação do professor habilitado com suas atividades didático-pedagógicas em sala de aula. O papel do professor nesta proposta de ação educativa será de uma aproximação mais intensa com os alunos em sala de aula. Esta aproximação ocorrerá por meio de interações professor-aluno.

Espera-se que este artigo possa contribuir para que se amplie o debate do papel da escola, ao fornecer ferramentas de ensino ao aluno, para que ele possa fazer uma leitura crítica, e também aceitar as novas formas de ensino. Com esta pesquisa- ação possamos ter evidenciado como a metodologia ativa pode abrir um mundo de possibilidades e propiciar momentos de experiências para o aluno, mediadas por estruturas culturais, proporcionando um crescimento significativo na prática do dia a dia da sala de aula e fora dela. 


\section{REFERÊNCIAS}

ABREU, M.C. \& MASSETTO, M. T. O professor universitário em aula. São Paulo: MG Editores, 1990.

BERGMANN, Jonathan \& SAMS, Aaron. Sala de aula invertida: uma metodologia ativa de aprendizagem. Rio de Janeiro: LTC, 2012.

FREIRE, Paulo. Pedagogia do oprimido. São Paulo: Paz e Terra, 1996. MEIRIEU, Philippe. Aprender... sim, mas como? 7. ed. Porto Alegre: Artes Médicas, 1998.

PERRENOUD, Philippe. Construir as competências desde a escola. Porto Alegre: Artes Médicas Sul, 1997 